\title{
A Rare Cause of Inguinal Herniation: Bladder Herniation Two Cases Report
}

\author{
Yasemin Gunduz ${ }^{\mathrm{a}, \mathrm{b}}$, Lacin Tatli Ayhan ${ }^{\mathrm{a}}$, Kiyasettin Asila, Yakup Ersel Aksoy
}

\begin{abstract}
Inguinal bladder hernias occur in $1 \%-4 \%$ of cases of inguinal hernias and are difficult to diagnosis preoperatively. In this report, radiological findings of two cases with inguinal bladder hernia were presented and the importance of the imaging modalities in preoperative diagnosis was emphasized.
\end{abstract}

Keywords: Inguinal herniation; Bladder; Diagnosis

\section{Introduction}

Despite the high incidence of inguinal hernias, bladder involvement occurs in $1 \%-4 \%$ of cases. Bladder hernia is often presenting in obese men aged 50 to 70 . The diagnosis of bladder involvement is often difficult and are usually found incidentally during radiographic evaluation or at the time of herniorrhaphy. Most bladder hernias are direct and most cases occur on the right side $[1,2]$. Most cases are asymptomatic. Hematuria, flank pain and to the development of obstructive uropathy can be caused by the content of inguinal hernias [3]. Herein, we presented two different cases with inguinal bladder hernia.

\section{Case Report}

\section{Case 1}

A 67-year-old man was consulted to our radiology clinic

\footnotetext{
Manuscript accepted for publication April 26, 2013

${ }^{a}$ Deparment of Radiology, Sakarya University Medical Faculty, Sakarya, Turkey

${ }^{\mathrm{b}}$ Corresponding author : Yasemin Gunduz, Sakarya University Medical Faculty, Deparment of Radiology, 54100, Korucuk, Sakarya, Turkey.

Email: dryasemingunduz@yahoo.com
}

doi: http://dx.doi.org/10.4021/jmc1282w complaining of recurrent episodes of microscopic hematuria and left-sided flank pain. He had no history of trauma, medication usage or significant family disorder. His additional comorbidities included hypertension, hyperlipidemia and benign prostate hyperplasia. There were no remarkable findings on abdominal palpation. Intravenous and oral contrast enhanced abdominal computed tomography (spiral multislice thin section scan) showed herniation through his left inguinal canal. Computed tomography (CT) revealed that a left inguinal hernia with fluid density lesion continuous with right lateral bladder wall. No bowel was contained in the hernia (Fig. 1, 2).

\section{Case 2}

65-year-old male patient was referred for control CT to our clinic. He also had a history of renal cell carcinoma treated successfully with left nefrectomy two years ago. The patient had no urinary symptoms or previous episodes of urinary retention. Renal functionaal tests and age-specific serum prostate-specific antigen level were normal. CT revealed a left inguinal hernia. Herniation of the bladder was better demonstrated on sagittal and coronal reformatted images (Fig. 3).

\section{Discussion}

The possible etiopathogenic factors for bladder hernias; chronically distended bladder, bladder outlet obstruction, decreased bladder tone, obesity, and weakness of the pelvic wall $[4,5]$. Our two cases had problem of bladder outlet obstruction but were not obese. Inguinal bladder hernias are usually asymptomatic. Asymptomatic inguinal bladder hernias are frequently diagnosed incidentally. However, several complications have been reported with inguinal hernias as urinary tract infections, obstructive uropathy and bladder infarctions requiring subtotal cystectomy [6-8]. In our cases, the bladder hernia was diagnosed perioperatively, and they had no specific symptoms that prompted consideration of bladder hernia.

In cases of large inguinal bladder hernias, typically, patients present with scrotal or inguinal swelling and occasion- 

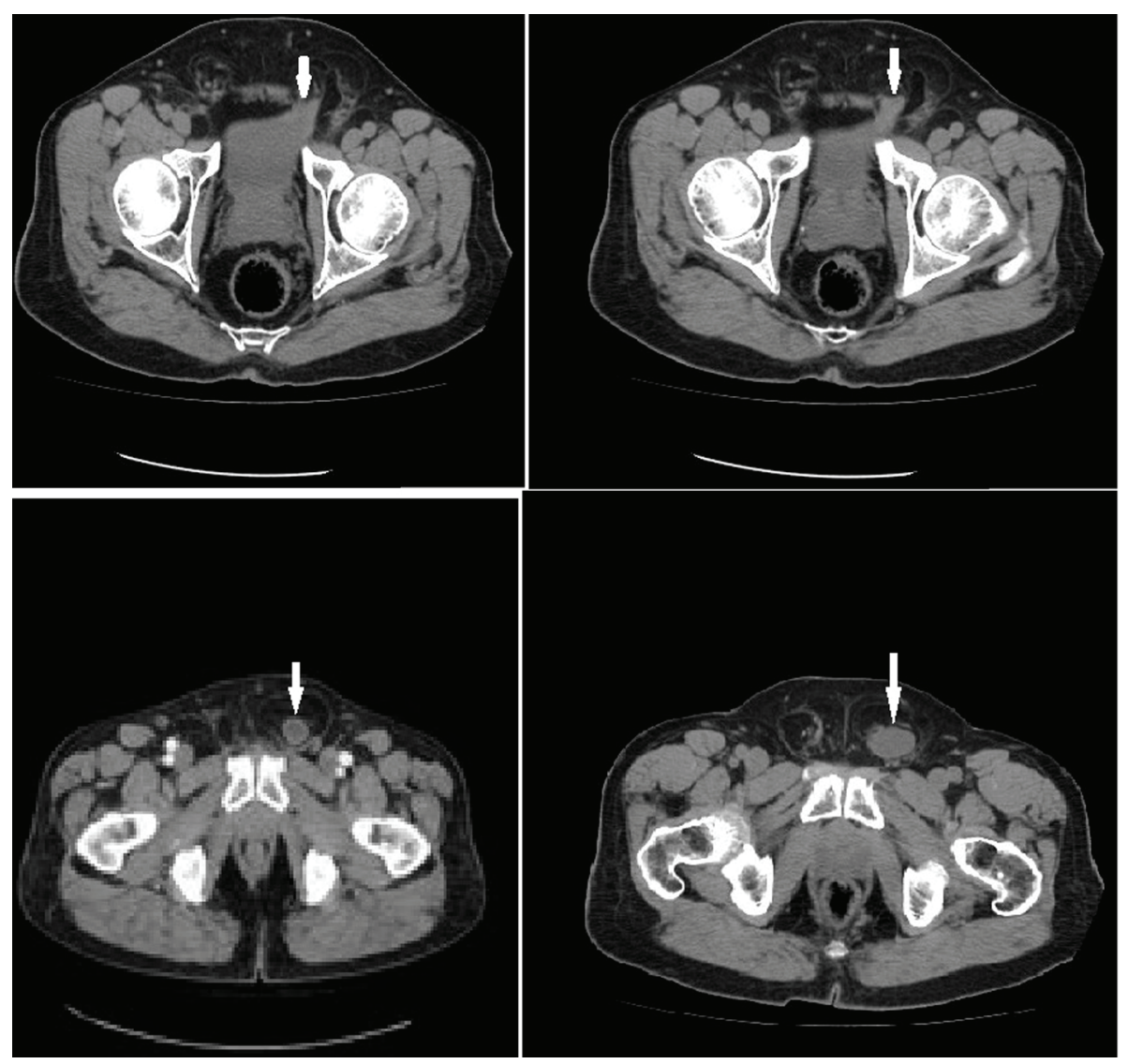

Figure 1. Axial CT scan demonstrated the left upper part of the bladder herniated into the inguinal canal. Inguinal canal had not any bowel segment (arrows).

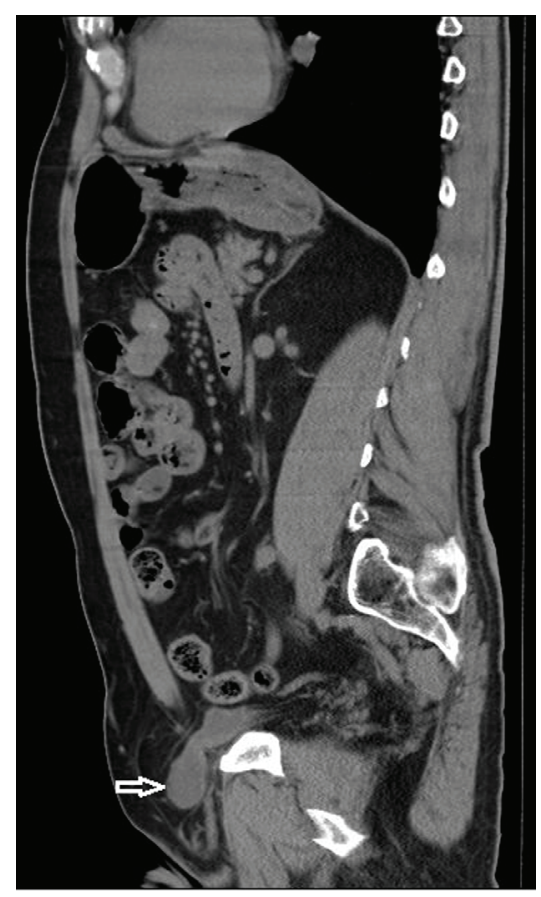

Figure 2. Sagittal reconstructed images demonstrated the herniation of the bladder into the inguinal canal (arrow).

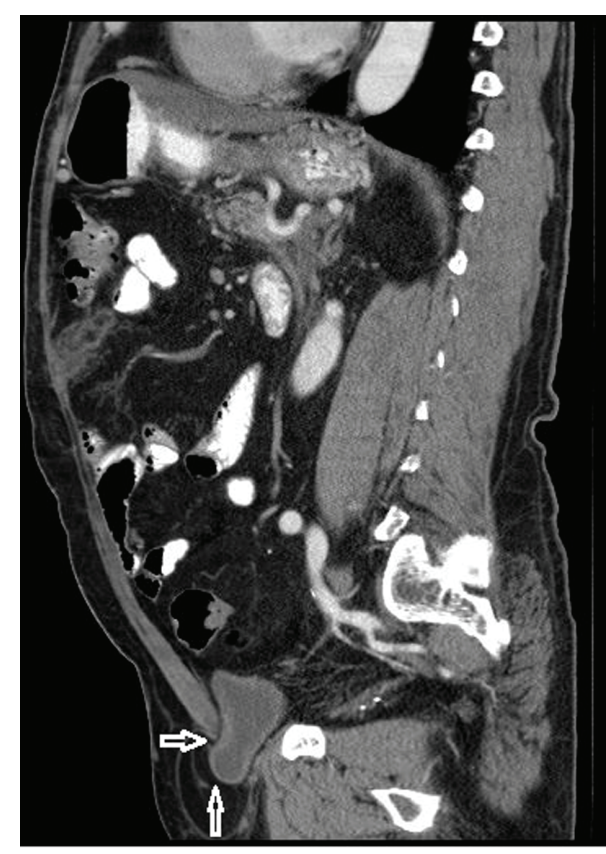

Figure 3. Sagittal and coronal reconstructed images better demonstrates the herniation of the bladder into the inguinal canal (arrows). 
ally the classic complaint of double voiding. Manual compression of the hernia after voiding is reported to be a more spesific finding $[9,10]$. Although, the importance of preoperative diagnosis of bladder hernias has been emphasized in order to reduce risk of bladder injury during hernia repair, less than $7 \%$ of bladder hernias are diagnosed before surgery. The risk of bladder injury during herniorrhaphy has been reported as 12\% [11]. Radiologic diagnosis can be established by cystography, intravenous pyelography (IVP), CT scan, or ultrasonography. However, CT is the most important diagnostic modality, as it can identify the content of hernia (bowel/omentum) and rule out associated complications like strangulation and hydronephrosis [5, 10, 12]. Especially in patients with large lesions, angulation of the base of the bladder anteriorly and inferiorly is the CT sign of a bladder herniation and it is possible to follow the bladder down into the inguinal or femoral canal as in our case. Reconstructions along sagittal or coronal planes can be useful [13].

MRI can identify bladder hernias; such lesions can be detected during studies of the abdomen and pelvis performed for another cause, or MRI can be used to clarify the findings seen on urography or sonography. However, the findings observed in axial, sagittal or coronal images planes parallel those seen on CT [14]. In the first case, the diagnosis of bladder hernia was missed preoperatively even though CT scan and reconstructions was used.

The standard treatment for inguinal bladder hernias is either reduction or resection of the herniated part bladder followed by surgical repair (herniorrhaphy) [1].

As a result, our cases illustrate a rare presentation of inguinal hernia, it is often diagnosed intraoperatively during herniorrhaphy or is identified after intraoperative injury. Accurate diagnosis can be readily established radiologically, can identify the anatomical deformity and any potential complications, such as bladder or bowel infarction.

\section{References}

1. Kim KH, Kim MU, Jeong WJ, Lee YS, Park KK, Chung MS, Chung BH, et al. Incidentally detected inguinoscrotal bladder hernia. Korean J Urol. 2011;52(1):71-73.
2. Oruc MT, Akbulut Z, Ozozan O, Coskun F. Urological findings in inguinal hernias: a case report and review of the literature. Hernia. 2004;8(1):76-79.

3. Ansari K, Keramati MR, Rezaei Kalantari K, Jafari M, Godazandeh G, Pakzad M. Gross hematuria as the presentation of an inguinoscrotal hernia: a case report. J Med Case Rep. 2011;5:561.

4. Bisharat M, O'Donnell ME, Thompson T, MacKenzie N, Kirkpatrick D, Spence RA, Lee J. Complications of inguinoscrotal bladder hernias: a case series. Hernia. 2009;13(1):81-84.

5. Gomella LG, Spires SM, Burton JM, Ram MD, Flanigan RC. The surgical implications of herniation of the urinary bladder. Arch Surg. 1985;120(8):964-967.

6. Fisher PC, Hollenbeck BK, Montgomery JS, Underwood $\mathrm{W}, 3 \mathrm{rd}$. Inguinal bladder hernia masking bowel ischemia. Urology. 2004;63(1):175-176.

7. Laniewski PJ, Watters GR, Tomlinson P. Herniation of the bladder trigone into an inguinal hernia causing acute urinary obstruction and acute renal failure. J Urol. 1996;156(4):1438-1439.

8. Vindlacheruvu RR, Zayyan K, Burgess NA, Wharton SB, Dunn DC. Extensive bladder infarction in a strangulated inguinal hernia. Br J Urol. 1996;77(6):926-927.

9. Wagner AA, Arcand P, Bamberger MH. Acute renal failure resulting from huge inguinal bladder hernia. Urology. 2004;64(1):156-157.

10. Shelef I, Farber B, Hertzanu Y. Massive bladder hernia: ultrasonographic imaging in two cases. $\mathrm{Br} \mathrm{J}$ Urol. 1998;81(3):492-493.

11. Catalano O. US evaluation of inguinoscrotal bladder hernias: report of three cases. Clin Imaging. 1997;21(2):126-128.

12. Casas JD, Mariscal A, Barluenga E. Scrotal cystocele: US and CT findings in two cases. Comput Med Imaging Graph. 1998;22(1):53-56.

13. Izes BA, Larsen CR, Izes JK, Malone MJ. Computerized tomographic appearance of hernias of the bladder. J Urol. 1993;149(5):1002-1005.

14. Bacigalupo LE, Bertolotto M, Barbiera F, Pavlica P, Lagalla R, Mucelli RS, Derchi LE. Imaging of urinary bladder hernias. AJR Am J Roentgenol. 2005;184(2):546-551. 